\title{
Regional left ventricular wall motion from first-pass radionuclide angiocardiography using an Anger camera Experimental and clinical study
}

\author{
S WALTON, E A DONALDSON, D J ROWLANDS, R A SHIELDS, H J TESTA, \\ C WRIGLEY \\ From the Departments of Cardiology, Nuclear Medicine and Medical Physics, Manchester Royal Infirmary
}

SUMMARY Experimental studies with a balloon phantom, and clinical studies were performed to evaluate first-pass radionuclide angiocardiography using a gamma camera in the assessment of regional wall motion.

The phantom studies showed that choice of isocount contour was not critical in edge detection. Adequate count densities could be achieved, but only at the expense of temporal resolution.

The clinical studies disclosed a good correlation with radiography in normal subjects and those with diffuse ventricular disease but a poor correlation in subjects with localised abnormalities of wall motion.

Radionuclide studies of the cardiac blood pools can be performed either during the first pass through the central circulation of a peripherally injected radionuclide bolus or when a blood pool tracer has come to equilibrium.

The first pass technique has several theoretical advantages over the equilibrium approach. The short data accumulation time ( 30 to $40 \mathrm{~s}$ ) makes the method particularly suitable for the study of seriously ill subjects who may have difficulty lying still and for the demonstration of short-lived abnormalities. The good temporal separation between right and left heart phases of bolus transit means that the left ventricle can be studied in the right anterior oblique (RAO) view without interference from activity in the overlying right ventricle. Finally, background levels are low.

The major disadvantage of first-pass studies derives from the limited performance of conventional gamma cameras in dealing with high count rates. The resulting reduction in efficiency of detection of emitted radiation leads to the accumulation of left ventricular images from a relatively small number of scintillations (or counts), thereby compromising image resolution. Multicrystal cameras have been developed with better response to high count rates, but at the expense of spatial resolution and energy discrimination.

Received for publication 21 February 1980
The purpose of this study was to determine how many counts per image were required for wall motion studies and to decide whether or not conventional gamma cameras were suitable. Both experimental studies using a balloon phantom and clinical studies were performed.

\section{Methods}

\section{(a) PHANTOM STUDIES}

The apparatus consisted of a fluid filled balloon suspended in a water bath at a depth of approximately $6 \mathrm{~cm} .{ }^{99} \mathrm{Tc}^{\mathrm{m}}$ as pertechnetate was added to the balloon which was imaged at volumes of $\mathbf{5 0}$ and $100 \mathrm{ml}$. A series of images was accumulated using a gamma camera and computer system. Each stored frame contained 1000 counts from the balloon and independent frames were summed to examine the effect of improving statistical accuracy. Background activity was varied by adding tracer to the water bath. An isocount contour technique was used to delineate the edge of the balloon image. Image dimensions were compared with actual dimensions from photographs.

\section{(b) CLINICAL STUDIES}

Forty-three subjects with a variety of cardiac disorders were studied by first-pass radionuclide angiocardiography. $15 \mathrm{mCi}{ }^{99} \mathrm{Tc}^{\mathrm{m}}$ pertechnetate 
were injected intravenously as a bolus and the first pass of tracer through the central circulation was detected by a gamma camera placed in the $30^{\circ}$ RAO position over the praecordium. Data were recorded in list mode and stored on magnetic disc. A left ventricular activity-time curve was used to identify individual cardiac cycles (intrinsic gating) during the left heart phase of bolus transit and each cycle was divided into eight equal time intervals. Data from corresponding intervals in successive cycles were summed to produce a series of images-a representative cine cycle. The 20 per cent isocount contour was arbitrarily chosen to represent the edge of the image. Movement of this contour was plotted as a third dimension against two axes representing (1) distance around the perimeter and (2) time from end-diastole to end-diastole. Values of equal displacement were joined to form a contour map. ${ }^{1}$ The advantage of this form of presentation is that it is not necessary to identify the plane of the aortic valve which can be difficult in these images. Wall motion was considered in anterior, apical, and inferior ventricular regions and was classified as normal if there was inward displacement of two contour levels $(1 \mathrm{~cm})$ from the end-diastolic position. Movement inward of less than two contour levels, no movement, and outward systolic movement were classified as abnormal.

Each subject underwent radiographic ventriculography in the same view within two days. There were no significant changes of treatment between the two examinations. Again wall motion was considered in anterior, apical, and inferior regions and was classified as normal or abnormal by an experienced observer with no knowledge of the radionuclide results. The results were compared region by region with the radionuclide results.

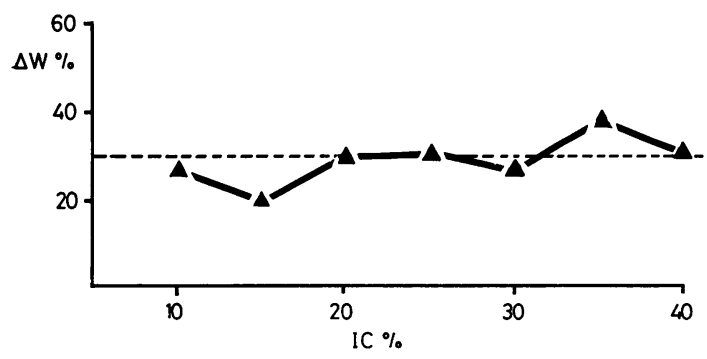

Fig. 1 The effect of choice of isocount contour on the apparent change in width of the balloon phantom as it was emptied from $100 \mathrm{ml}$ to $50 \mathrm{ml} . \mathrm{W} \%$, change in width as a percentage of $100 \mathrm{ml}$ width; IC\%, isocount contour as a percentage of peak counts; - - - actual change (from photograph); - apparent change.

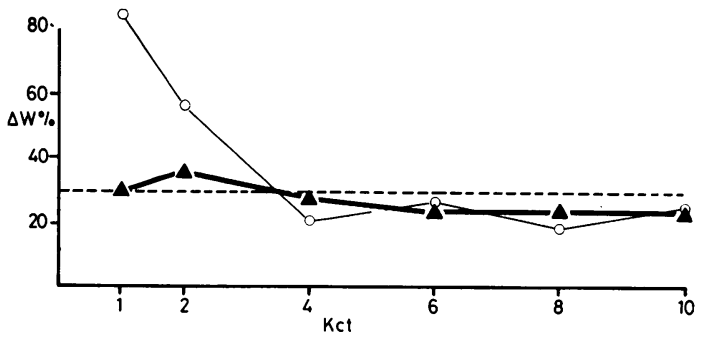

Fig. 2 The effect of increasing count density on the apparent change in width of the balloon phantom as it was emptied from $100 \mathrm{ml}$ to $50 \mathrm{ml}$. W\%, change in width as a percentage of $100 \mathrm{ml}$ width; Kct, kilo-counts per image for the $100 \mathrm{ml}$ balloon; $\mathbf{\Delta}$, no added background; $\bigcirc$, background 40 per cent; -- - - actual change (from photograph)

All studies were performed using a Radicamera Mk II with a standard, parallel hole collimator, and a Nuclear Data computer system.

\section{Results}

\section{(a) PHANTOM STUDIES}

The results are expressed in Fig. 1 and 2; those relating to width and area were similar; those relating to width have been chosen for illustration because this measurement has more relevance to wall motion studies and it avoids repetition. On emptying the balloon from 100 to $50 \mathrm{ml}$ there was a 30 per cent decrease in maximum width. Fig. 1 illustrates the effect of taking different isocount contours to represent the image edge. Though the choice of isocount contour affected the apparent absolute size of the balloon, the estimate of change in size was independent of isocount contour between 10 and 40 per cent.

Fig. 2 illustrates the effect of varying image counts at two different background levels. With background up to 40 per cent it is possible to obtain reliable estimates of change in width provided that 4000 counts are accumulated in the region of interest.

\section{(b) CL'NICAL STUDIES}

Fig. 3 shows an 8 frame cine cycle and Fig. 4 a contour map. The number of counts in each ventricular image varied between 1000 and 4000 at end-diastole. Background levels varied between 15 and 35 per cent of peak intraventricular activity.

Table 1 shows that in the group as a whole there was a good correlation between radiographic and radionuclide angiocardiography. Twenty-three subjects had radiographically normal ventricles. In 
Fig. 3 Representative cine cycle. ED, end-diastole; $E S$, end-systole; $L V$, left ventricle; $L A$, left atrium; Ao, aorta.
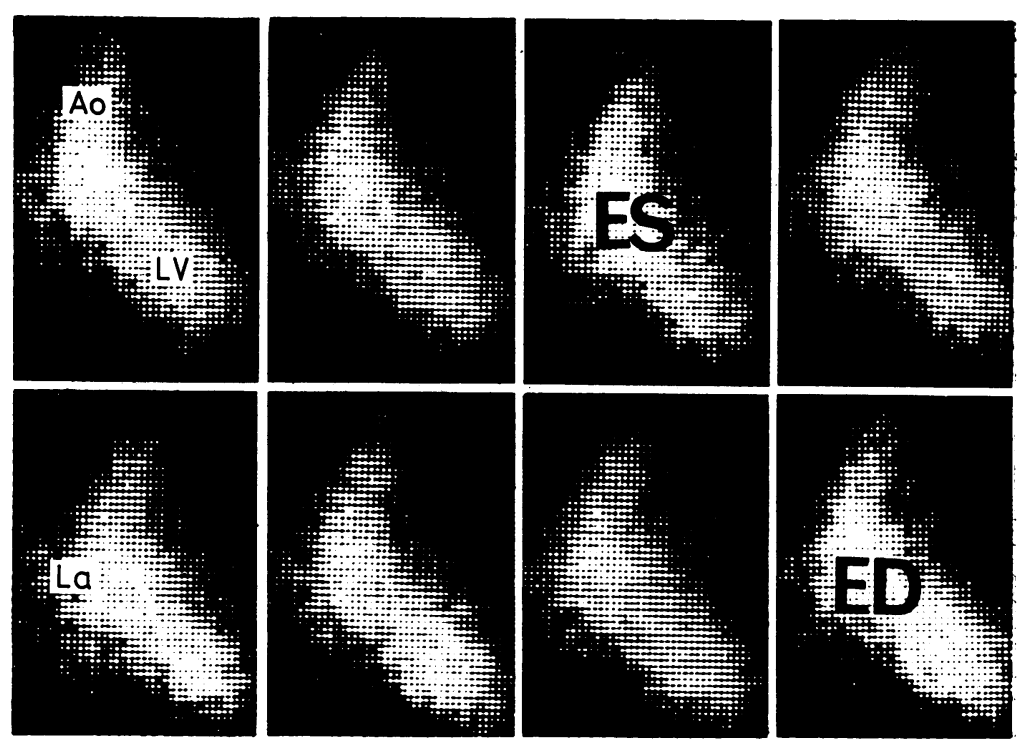

these subjects 68 out of 75 regions were normal on the radionuclide study. Ten subjects had diffusely abnormal ventricles and in these the nuclear technique showed abnormalities in 25 out of 30 regions. Results were less good in those with localised wall motion abnormalities as shown in Table 2.

\section{Discussion}

The number of counts in each image depends upon count rate, data collection time, and temporal resolution. Therefore, in equilibrium studies it is most easily increased by prolonging data collection time. In first-pass studies, which have a finite interval for data collection, it can be done by improving detection efficiency (multicrystal cameras) or by decreasing temporal resolution.

Using equilibrium studies, Zaret et al. ${ }^{2}$ accumulated 300000 counts in each total end-diastolic image, and Rigo et al., ${ }^{3} 200000$ counts, collecting data from 200 to 400 cardiac cycles. Improving temporal resolution by producing 80 to 100 frame representative cine cycles ${ }^{4}$ necessitated data summation from 1200 to 1500 cycles. Some groups have attempted to reduce data collection time and the risk of motion artefact. Sneed et al. ${ }^{5}$ accumulated 150000 counts over four minutes with a temporal resolution of nine frames for each representative cycle. Bacharach et al. ${ }^{6}$ argue that no advantage is gained by imaging for 10 rather than two and a half minutes. This group has used the short data collection time to study transient, exercise, and

drug induced changes. ${ }^{7-10}$ The figures quoted above refer to the total counts in an end-diastolic frame. This is not the same as intraventricular counts. Maddox et al. ${ }^{11}$ estimated that out of 300000 counts in an end-diastolic frame only 30000 came from the ventricle. Burrow et al. ${ }^{12}$ calculate 18500 counts from the left ventricle after background correction.

Using a multicrystal camera for first-pass studies, Schad ${ }^{13}$ found 30000 counts in the uncorrected end-diastolic frame of which 3000 to 13000 (mean $9600)$ actually came from the ventricle. This was with a time resolution of $50 \mathrm{~ms}$. Marshall et al. ${ }^{14} 15$ using similar equipment but sampling from fewer cardiac cycles, achieved $3300 \pm 2000$ counts for the ventricular image. Again using similar equipment, Bodenheimer et al. ${ }^{16}$ could obtain 3723 to 10268 (mean 6221) counts for each ventricular image after background subtraction.

First-pass wall motion studies have also been performed with single crystal cameras. Kostuk et $a .^{17}$ and Jengo et al. ${ }^{18}$ do not quote count densities. Pachinger et al. ${ }^{19}$ quote 14000 to 17000 counts for the total field in the right ventricular phase of bolus transit. Peak activity in the left heart phase and counts for each image are not quoted. Hecht et al. ${ }^{20}$ claim 79 counts in the ventricle from the end-diastolic frame and sum 10 to 12 such frames producing approximately 800 to 1000 counts for the ventricle in the representative cine cycle. They believe that objective methods of edge detection may compensate for the relatively low count density. 


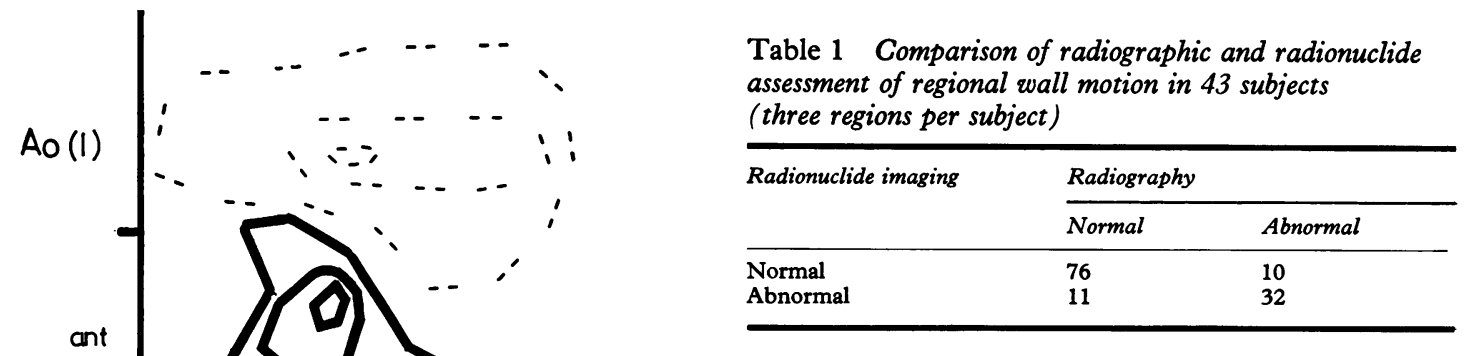

The admittedly simplified phantom studies suggest that, at background levels comparable to clinical studies, 4000 counts for the end-diastolic image should give a reasonable estimate of wall motion with an ejection fraction of 50 per cent. Fewer counts than this may give correct estimates under more favourable background levels or if ejection is less. As the counts per $100 \mathrm{ml}$ balloon fall below 2000 there is a progressive tendency to overestimate the percentage decrease in width. This effect is produced by a progressive underestimation of the size of the $50 \mathrm{ml}$ balloon in the presence of added background activity.

It was apparent that to achieve desired count density using this equipment a time resolution of eight frames per representative cycle was the maximum that could be achieved. Even then the figures are barely adequate. The limited temporal resolution is of less importance at end-diastole because of the relatively prolonged maintenance of the end-diastolic position, but it may well underestimate the maximum extent of systolic inward movement. The phantom studies also showed that choice of isocount contour for edge definition has little effect on results (Fig. 1).

It is not unreasonable to expect that future developments in instrumentation may lead to a fivefold increase in maximum count rate; this should be a major benefit to first-pass studies.

Radiographic cineangiography is the accepted standard by which other techniques for the evaluation of wall motion are assessed. Certain factors would, however, lead us to expect a less than complete agreement between radionuclide and

Fig. 4 Contour map representation of wall motion. The vertical axis corresponds to position along the perimeter of the left ventricle, left atrium, and aorta. The horizontal axis represents time into the cardiac cycle. Each solid contour represents a movement inwards of $5 \mathrm{~mm}$ from the end-diastolic position and each broken contour a movement of $5 \mathrm{~mm}$ outwards. Ao(1), left side of aortic root; $A o(r)$, right side of aortic root; $L V$, left ventricle; $L A$, left atrium; $E D$, end-diastole. Note inward movement of proximal anterior and inferior left ventricular walls with apical and distal anterior akinesis. Left atrium expands. Both walls of aorta move to the left but the left wall to a greater extent than the right. This represents movement of the aorta as a whole plus apparent systolic aortic expansion.
Table 2 Comparison of radiographic and radionuclide assessment of regional wall motion: eight subjects with localised abnormalities of wall motion by radiography (three regions per subject)

\begin{tabular}{lll}
\hline Radionuclide imaging & \multicolumn{2}{l}{ Radiography } \\
\cline { 2 - 3 } & Normal & Abnormal \\
\hline Normal & 8 & 5 \\
Abnormal & 4 & 7 \\
\hline
\end{tabular}


radiographic studies. Cardiac catheterisation is carried out on subjects who may be sedated and a considerable amount of emotional stress is involved. By the time ventriculography is performed the patient has been lying flat for some time. The injection of contrast material into the ventricle under pressure can affect wall motion, though perhaps not over the first five beats. ${ }^{21}$ In addition the two studies may not be directly comparable. Radiography provides strictly two-dimensional information whereas the radionuclide approach probably provides three-dimensional estimates of regional function. Finally, no correction is made in the radionuclide studies for movement of the heart as a whole whereas this is probably done automatically with subjective reporting of radiographic angiograms.

Table 1 shows a reasonable overall agreement between the two techniques. The results show a closer correlation in radiographically normal and diffusely abnormal ventricles (Tables 1 and 2) than in subjects with localised disease. In diffusely abnormal ventricles there is prolonged bolus transit which gives a greater opportunity for data collection. The ventricle is dilated and therefore end-diastolic counts are higher, as are end-systolic counts because of the reduced ejection fraction. In normal ventricles the end-diastolic counts are less and the good ejection fraction means low endsystolic counts. This should serve only to accentuate the normal appearance. In ventricles with good ejection despite localised wall motion disorders any underestimation of end-systolic dimension would tend to obscure the abnormality. In addition the spatial resolution may not be adequate to detect small areas of abnormality, especially when combined with limited temporal resolution.

\section{Conclusion}

First-pass wall motion studies place severe demands on conventional gamma cameras. In this study wall motion analysis was reasonably reliable in normal subjects and subjects with diffuse ventricular disease but not in subjects with more localised disorders of wall motion. Improved results can be expected with more sophisticated equipment.

This work was supported by the British Heart Foundation.

\section{References}

1 Gibson DG, Prewitt TA, Brown DJ. Analysis of left ventricular wall movement during isovolumic relaxation and its relation to coronary artery disease. Br Heart $\mathcal{F}$ 1975; 38: 1010-19.

2 Zaret BL, Strauss HW, Hurley PJ, Natarajan TK, Pitt B. A noninvasive scintiphotographic method for detecting regional ventricular dysfunction in man. $N$ Engl f Med 1971; 284: 1165-70.

3 Rigo P, Murray M, Strauss HW, Pitt B. Scintiphotographic evaluation of patients with suspected left ventricular aneurysm. Circulation 1974; 50: 985-91.

4 Green MV, Ostrow HG, Douglas MA, et al. High temporal resolution ECG-gated scintigraphic angiocardiography. $\mathcal{f}$ Nucl Med 1975; 16: 95-8.

5 Sneed A, Mishkin FS, Kaushik VS, Reese I. Radionuclide cinecardiography using minicomputer generated sequential gated images. $\mathrm{Br}$ Heart $\mathcal{f}$ 1977; 39: 982-7.

6 Bacharach SL, Green MV, Borer JS, Douglas MA, Ostrow HG, Johnston GS. A real-time system for multi-image gated cardiac studies. $\mathcal{F}$ Nucl Med 1977; 18: 79-84.

7 Borer JS, Bacharach SL, Green MV, Kent KM, Epstein SE, Johnston GS. Real-time radionuclide cineangiography in the noninvasive evaluation of global and regional left ventricular function at rest during exercise in patients with coronary-artery disease. $N$ Engl f Med 1977; 296: 839-44.

8 Borer JS, Bacharach SL, Green MV, Kent KM, Johnston GS, Epstein SE, Effect of nitroglycerine on exercise-induced abnormalities of left ventricular regional function and ejection fraction in coronary artery disease. Circulation 1978; 57: 314-20.

9 Bodenheimer MM, Banka VS, Fooshee CM, Gillespie JA, Helfant RH. Detection of coronary heart disease using radionuclide determined regional ejection fraction at rest and during hand grip exercise: correlation with coronary arteriography. Circulation 1978; 58: 640-8.

10 Marshall RC, Berger HJ, Reduto LA, Cohen LS, Gottschalk A, Zaret BL. Assessment of cardiac performance with quantitative radionuclide angiocardiography: effects of oral propranolol on global and regional left ventricular function in coronary artery disease. Circulation 1978; 58: 808-14.

11 Maddox DE, Holman BL, Wynne J, et al. Ejection fraction image: a noninvasive index of regional left ventricular wall motion. Am $\mathcal{F}$ Cardiol 1978; 41: $1230-87$.

12 Burow RD, Strauss HW, Singleton R, et al. Analysis of left ventricular function from multiple gated acquisition cardiac blood pool imaging. Circulation 1977; 56: 1024-8.

13 Schad N. Nontraumatic assessment of left ventricular wall motion and regional stroke volume after myocardial infarction. $\mathcal{F}$ Nucl Med 1977; 18: 333-41.

14 Marshall RC, Berger HS, Costin JC, et al. Assessment of cardiac performance with quantitative radionuclide angiocardiography: sequential left ventricular ejection fraction, normalised left ventricular ejection rate, and regional wall motion. Circulation 1977; 56: 820-9.

15 Marshall RC, Berger HJ, Reduto LA, Gottschalk A, 
Zaret BL. Variability in sequential measures of left ventricular performance assessed with radionuclide angiocardiography. Am f Cardiol 1978; 41: 531-6.

16 Bodenheimer MM, Banka VS, Fooshee CM, Hermann GA, Helfant RH. Quantitative radionuclide angiography in the right anterior oblique view: comparison with contrast ventriculography. Am f Cardiol 1978; 41: 718-25.

17 Kostuk WJ, Ehsani AA, Karliner JS, et al. Left ventricular performance after myocardial infarction assessed by radioisotope angiocardiography. Circulation 1973; 47: 242-9.

18 Jengo JA, Mena I, Blaufuss A, Criley JM. Evaluation of left ventricular function (ejection fraction and segmental wall motion) by single pass radioisotope angiography. Circulation 1978; 57: 326-32.

19 Pachinger O, Ogris E, Probst P, Joskowics G,
Sochor H, Kaindl F. Assessment of left ventricular performance and myocardial viability using quantitative radioisotope techniques. $B r$ Heart $\mathcal{f}$ 1979; 42: 205-13.

20 Hecht HS, Mirell SG, Rolett EL, Blahd WH. Leftventricular ejection fraction and segmental wall motion by peripheral first pass radionuclide angiography. $\mathcal{F}$ Nucl Med 1978; 19: 17-23.

21 Karliner JS, Bouchard RJ, Gault JH. Haemodynamic effects of angiographic contrast material in man: a beat-by-beat analysis. $B r$ Heart $\mathcal{F}$ 1972; 34: 347-55.

Requests for reprints to Dr S Walton, Department of Cardiology, The Middlesex Hospital, Mortimer Street, London W1N 8AA. 